\title{
Pecan Nut and Kernel Traits Are Related to Shelling Efficiency
}

\author{
T.E. Thompson ${ }^{1}$ and L.J. Grauke ${ }^{2}$ \\ Agricultural Research Service, U.S. Department of Agriculture, College \\ Station, TX 77840
}

Additional index words. Carya illinoinensis, breeding, genetics, nut quality

\begin{abstract}
The U.S. Dept. of Agriculture, Agricultural Research Service conducts the largest and oldest pecan [Carya illinoinensis (Wangenh.) K. Koch] breeding program in the world. This program evaluates thousands of nut and kernel samples each year using a standard nut and kernel evaluation system developed and refined for more than 70 years. This report relates the effectiveness of these evaluations to commercial shelling efficiency by direct comparison of these data to commercially shelled samples from the same clone performance test. Visual ratings of shelled kernel samples $(1-5$, with $1=$ best) were correlated with time required to hand clean kernel samples $(r=0.55)$. As percent kernel increased, visual ratings of shelled kernels improved (decreased) $(r=-\mathbf{0 . 7 3})$. More intact halves were recovered from shelled samples with the best (lowest) visual ratings $(r=-0.67)$. Conversely, fewer pieces of any size were present in samples with the best visual ratings. Visual ratings improved as nut density decreased $(r=0.33)$. Samples with the lightest kernel color also had the best visual ratings $(r=0.38)$. These data show that the standard U.S. Dept. of Agriculture pecan nut and kernel evaluation system needs to be refined by modifying selection pressure placed on various standard evaluation traits.
\end{abstract}

A century ago, almost all pecans were collected from natural stands (native trees). The nuts were small and had thick shells that were hard to remove. The portion of the U.S. crop that is collected from native trees has steadily decreased due to habitat annihilation and poor economic returns. Breeding efforts to improve pecan nut quality have been successful (Grauke and Thompson, 1996).

The U.S. Dept. of Agriculture, Agricultural Research Service pecan breeding program is headquartered at College Station, and Brownwood, Texas. This program, which began in $\approx 1932$, has released 24 cultivars in cooperation with various state agricultural experiment stations ( Thompson and Grauke, 1991; Thompson and Young, 1985). Controlled crosses are made between selected parents, trees are evaluated under field conditions, and the best clones are selected for further testing in the National Pecan Advanced Clone Testing System (NPACTS). In NPACTS orchards, clones are vegetatively propagated and their performance is compared to standard commercial cultivars. Tests are conducted in several major pecan production areas to determine specific environmental suitability of new cultivars. The average time from crossing to cultivar release is 27.25 years (shortest time 13 years; longest time 60 years). Considering the year to make the controlled cross, the 10-year cycle for evaluation in the Basic Breeding Program (BBP), and the 9- to 15-year evaluation period in NPACTS, a development time of 20 years is required.

Received for publication 4 Sept. 2002. Accepted for publication 4 Feb. 2003. Special thanks to Mr. Kenneth Fangue, Pecan Grower, Hempstead, Texas, for providing equipment and helping to conduct this shelling test.

${ }^{1}$ Research Geneticist.

${ }^{2}$ Research Horticulturist.
Since about $90 \%$ of pecans are shelled before retail sale, and all are eventually shelled, ease of shelling and yield of large kernel halves or pieces is of major economic importance. Yet little is known about the effects of basic nut and kernel traits in determining ease of machine shelling. In this breeding program, ease of shelling and removal of packing material from the dorsal grooves, ventral grooves, and other kernel surfaces are major continuous selection criteria.

In the NPACTS program, basic nut evaluation is routine, but the relationship of these measurements to actual commercial shelling efficiency has been inadequate. Therefore, the objective of this study was to compare data collected in the laboratory with results obtained from commercial shelling operations.

\section{Materials and Methods}

Nut samples were collected from trees in an NPACTS test established on a Deleon silty clay soil (fine, mixed, thermic Udertic Haplustolls) at Brownwood, Texas. Rootstocks were grafted in Apr. 1996 to 50 clones (Table 1), consisting of 46 advanced selections from the BBP, and four standard control cultivars ('Desirable', 'Navaho', 'Pawnee', and 'Wichita'). Spacing was $9.14 \mathrm{~m} \times 10.7 \mathrm{~m}$, with single-tree plots, and eight replications. Standard Texas Agricultural Extension Service recommendations for culture and irrigation were followed.

During Sept. and Oct. 2001, trees were individually hand harvested. The nut samples were dried at $35^{\circ} \mathrm{C}$ for 3 to $10 \mathrm{~d}$ until moisture content had been reduced to about $4 \%$. Samples were then stored in brown paper bags under frost-free refrigeration at $2{ }^{\circ} \mathrm{C}$.

A five-nut sample from each of eight singletree replications was analyzed according to the standard NPACTS nut analysis system. A flow chart of procedures and acronyms were assigned to different parameters measured (Fig. 1). Data included nut length (NL), nut width (diameter across suture) (NWth), nut height (diameter perpendicular to suture) $(\mathrm{NH})$, nut weight (NW), and nut buoyancy (NB). Nut buoyancy was determined by submerging individual nuts in a weighted screen container in water below a Mettler digital balance (modified method described by Waugh, 1938). The balance was supported by a wooden frame above a container of water. The difference in weight of the empty screen container suspended in the water and the decreased weight of the container with the nut submerged was buoyancy. These whole-nut data were used to calculate nut length:width ratio (NL:NWth), nut length:height ratio (NL:NH), nut volume (NV), and nut density (ND). Buoyancy in grams was added to nut weight to determine nut volume in milliliters since density of water is 1.0 . Nut density was determined by dividing weight by volume.

Nuts were then individually shelled and kernel weight $(\mathrm{KW})$ was determined, along with percent packing material retained in the dorsal and ventral grooves (DGP\% and VGP\%, respectively), percent testa covered with fuzz (Fz\%), and 1-5 visual kernel color rating (1 = best or lightest) (KC) (Thompson et al., 1996). Kernel percent (kernel weight divided by nut weight) (K\%) was also determined. Shell weight was used to determine the shell weight to nut volume ratio (ShWt:NV).

Bulked nut samples from the above NPACTS test were also used to run a cracking test and a shelling test (Fig. 1). In the cracking experiment, a few nuts were used to set the Edible Nut Cracker (Meyer Manufacturing Co., San Antonio, Texas) before each of the 500-g test samples was cracked. This test sample was then screened using a wire screen with square $6.35-\mathrm{mm}$ openings. Small kernel fragments $>5 \mathrm{~mm}$ in diameter that passed through this screen were removed, and the remaining shell portion was weighed. Percent shell fragments was then computed.

Alarger 2.5-kg nut sample was also cracked using the Meyer cracker, adjusting the machine for every sample. The sample was then shelled using a pecan sheller (Thomson, model 0092 , T.I. Thomson Inc., Cairo, Ga.). This sheller produced two samples: one mostly kernels, and the other mostly shells (Fig. 1). The kernel fraction was rated by Mr. Kenneth Fangue, an experienced commercial pecan sheller. $\mathrm{He}$ made a single visual rating on each kernel fraction (1-5, with 1 the most desirable). In making this rating, he considered ease of shelling based upon general appearance, amount of shell retained on kernels, amount of dorsal and ventral packing material retained on kernels, degree of kernel breakup, and other general shelling traits. He also made general comments on shelling traits.

The kernel and shell portions from the shelling process were further analyzed in the laboratory. The kernel fraction was divided into four subsamples, one of which was analyzed further. Percent packing material retained in the dorsal grooves (ShDGP\%), percent pack- 
Table 1. USDA-ARS selections and standard cultivars in 2001 pecan shelling test. Clone numbers indicate last two digits of year cross was made, cross number, and seed or clone number. Fangue visual rating of shelled kernel samples are from 1-5, $1=$ best. Time is minutes to hand-clean kernel samples from sheller. $\mathrm{ShK} \% \mathrm{~K}$ is percent kernel of shelled kernel fraction. See Fig. 1 for additional notation.

\begin{tabular}{|c|c|c|c|c|c|c|c|c|}
\hline Clone & $\begin{array}{c}\text { Female } \\
\text { parent }\end{array}$ & $\begin{array}{c}\text { Male } \\
\text { parent }\end{array}$ & Nut shape & $\begin{array}{l}\text { Visual } \\
\text { rating }\end{array}$ & $\begin{array}{c}\text { Time } \\
\left(\min \cdot \mathrm{kg}^{-1}\right)\end{array}$ & ShK $\% \mathrm{~K}$ & $\mathrm{~K}(\%)$ & $\begin{array}{c}\text { ShWt:NV } \\
\left(\mathrm{g} \cdot \mathrm{mL}^{-1}\right)\end{array}$ \\
\hline $81-07-0133$ & Wichita & Cherokee & Oblong elliptic & 3 & 72.39 & 0.818 & 53.4 & 0.36 \\
\hline $81-07-0502$ & Wichita & Cherokee & Ovate & 5 & 85.62 & 0.761 & 53.7 & 0.39 \\
\hline $82-10-0003$ & Wichita & Pawnee & Elliptic & 1 & 47.13 & 0.861 & 53.8 & 0.38 \\
\hline $82-10-0135$ & Wichita & Pawnee & Oblong elliptic & 2 & 68.09 & 0.880 & 60.1 & 0.33 \\
\hline $82-10-0149$ & Wichita & Pawnee & Elliptic & 2 & 76.93 & 0.862 & 60.7 & 0.31 \\
\hline $82-13-0015$ & $53-9-1$ & Pawnee & Elliptic & 3 & 70.18 & 0.762 & 49.8 & 0.35 \\
\hline $82-16-0014$ & Pawnee & Wichita & Elliptic & 3 & 46.24 & 0.824 & 58.5 & 0.35 \\
\hline 83-03-0075 & Wichita & Pawnee & Elliptic & 2 & 67.07 & 0.896 & 61.2 & 0.32 \\
\hline 84-03-0030 & Cheyenne & Pawnee & Orbicular & 2 & 100.43 & 0.863 & 54.4 & 0.38 \\
\hline 85-01-0002 & BW-1 & Osage & Oblong elliptic & 1 & 52.54 & 0.940 & 56.6 & 0.33 \\
\hline $85-02-0225$ & Cheyenne & Pawnee & Oblong elliptic & 2 & 32.26 & 0.901 & 56.2 & 0.33 \\
\hline 85-03-0822 & Cheyenne & Creek & Oblong elliptic & 1 & 37.86 & 0.929 & 52.5 & 0.37 \\
\hline $86-02-0063$ & Wichita & Pawnee & Elliptic & 2 & 41.18 & 0.846 & 59.6 & 0.33 \\
\hline $86-02-0245$ & Wichita & Pawnee & Oblong & 5 & 91.80 & 0.781 & 56.3 & 0.38 \\
\hline $86-02-0255$ & Wichita & Pawnee & Oblong & 1 & 57.89 & 0.832 & 60.3 & 0.33 \\
\hline $86-02-0417$ & Wichita & Pawnee & Oblong & 3 & 70.14 & 0.791 & 53.9 & 0.38 \\
\hline $86-02-0486$ & Wichita & Pawnee & Oblong & 1 & 75.36 & 0.918 & 45.5 & 0.33 \\
\hline $86-02-1217$ & Wichita & Pawnee & Elliptic & 2 & 60.49 & 0.815 & 52.9 & 0.36 \\
\hline $86-02-1348$ & Wichita & Pawnee & Elliptic & 2 & 56.25 & 0.865 & 57.7 & 0.34 \\
\hline $86-02-1513$ & Wichita & Pawnee & Ovate & 1 & 35.78 & 0.862 & 57.6 & 0.35 \\
\hline $86-02-1516$ & Wichita & Pawnee & Elliptic & 2 & 66.45 & 0.821 & 50.8 & 0.35 \\
\hline $86-02-1568$ & Wichita & Pawnee & Oblong elliptic & 3 & 55.99 & 0.733 & 49.9 & 0.36 \\
\hline 86-02-1709 & Wichita & Pawnee & Oblong & 2 & 61.83 & 0.890 & 59.0 & 0.33 \\
\hline $86-02-1868$ & Wichita & Pawnee & Elliptic & 3 & 67.44 & 0.809 & 57.4 & 0.36 \\
\hline 86-02-1910 & Wichita & Pawnee & Oblong & 3 & 50.73 & 0.876 & 57.3 & 0.35 \\
\hline $86-02-2030$ & Wichita & Pawnee & Oblong elliptic & 4 & 76.92 & 0.754 & 57.4 & 0.35 \\
\hline $86-02-2186$ & Wichita & Pawnee & Oblong & 2 & 46.89 & 0.853 & 55.9 & 0.37 \\
\hline $86-02-2313$ & Wichita & Pawnee & Oblong elliptic & 2 & 62.85 & 0.858 & 58.3 & 0.33 \\
\hline $86-02-2645$ & Wichita & Pawnee & Oblong elliptic & 1 & 78.06 & 0.945 & 54.9 & 0.34 \\
\hline $86-02-2734$ & Wichita & Pawnee & Elliptic & 3 & 65.59 & 0.766 & 49.8 & 0.38 \\
\hline $86-02-2889$ & Wichita & Pawnee & Oblong & 1 & 63.36 & 0.875 & 57.4 & 0.31 \\
\hline 86-02-2899 & Wichita & Pawnee & Elliptic & 1 & 76.38 & 0.861 & 59.7 & 0.31 \\
\hline 86-03-0006 & Cheyenne & Pawnee & Ovate & 3 & 67.19 & 0.810 & 55.1 & 0.35 \\
\hline 86-03-0008 & Cheyenne & Pawnee & Oblong elliptic & 2 & 86.85 & 0.834 & 54.2 & 0.39 \\
\hline 86-03-0032 & Cheyenne & Pawnee & Ovate & 1 & 69.67 & 0.891 & 56.3 & 0.31 \\
\hline 86-03-0040 & Cheyenne & Pawnee & Elliptic & 5 & 167.08 & 0.657 & 56.6 & 0.37 \\
\hline 86-03-0072 & Cheyenne & Pawnee & Elliptic & 1 & 61.18 & 0.826 & 54.9 & 0.36 \\
\hline $86-03-0356$ & Cheyenne & Pawnee & Ovate & 3 & 80.68 & 0.723 & 55.3 & 0.38 \\
\hline $86-03-0357$ & Cheyenne & Pawnee & Elliptic & 3 & 63.73 & 0.771 & 57.3 & 0.34 \\
\hline $86-03-0505$ & Cheyenne & Pawnee & Elliptic & 2 & 44.06 & 0.932 & 64.9 & 0.29 \\
\hline $86-03-0624$ & Cheyenne & Pawnee & Ovate & 2 & 38.04 & 0.840 & 55.4 & 0.36 \\
\hline $86-03-0627$ & Cheyenne & Pawnee & Elliptic & 2 & 60.20 & 0.816 & 57.5 & 0.36 \\
\hline $86-03-0666$ & Cheyenne & Pawnee & Oblong elliptic & 3 & 73.70 & 0.787 & 61.1 & 0.31 \\
\hline 87-01-0016 & Cheyenne & Pawnee & Oblong elliptic & 1 & 44.89 & 0.817 & 56.5 & 0.34 \\
\hline $87-12-0029$ & Wichita & Pawnee & Oblong & 2 & 35.43 & 0.825 & 62.3 & 0.30 \\
\hline Desirable & Success & Jewett & Elliptic & 3 & 91.55 & 0.711 & 50.5 & 0.36 \\
\hline Navaho & $49-13-311$ & Wichita & Oblong elliptic & 1 & 38.69 & 0.925 & 58.5 & 0.32 \\
\hline Pawnee & Mohawk & Starking & Oblong elliptic & 1 & 44.81 & 0.899 & 56.2 & 0.37 \\
\hline Wichita & Halbert & Mahan & Oblong & 2 & 85.11 & 0.758 & 60.0 & 0.34 \\
\hline
\end{tabular}

ing material retained in the ventral grooves (ShVGP\%), and percent of kernel shoulders damaged in the cracking and shelling process (ShDSh\%) were determined. The subsample was then hand-cleaned, and time required per kilogram to clean was recorded (time). Weight of clean kernel, shell, and weight of insect-damaged kernels were recorded, and percent kernel (ShK\%) was computed. The cleaned kernel portion was then separated into four kernel size classes, each weighed, and percentage of each determined: complete halves ( $>80 \%$ intact) $(\mathrm{CH} \%)$, large pieces $(80 \%$ to $50 \%$ intact) (LP\%), small pieces (50\% to $25 \%$ intact) (SP\%), and remaining chips (Chips\%).

Kernel pieces in the shell portion out of shelling machine that were $>5$-mm diameter were removed by hand. Shell and kernel portions were weighed, and percent kernel in the shell portion was determined (ShShK\%).
The GLM and other procedures of SAS (SAS Institute, Cary, N.C.) were used in all statistical tests.

\section{Results and Discussion}

The cracking test was conducted to determine the amount of shell fragment that would be shattered and immediately removed from the nut. This could be an indication of how easily the shelling process could separate shell and kernel. The percent shell removed was not significantly different for the five subjective shellability ratings, although there was a slight trend with the most shell removed from the samples rated $1(1=11.0 \%, 2=10.7 \%, 3$ $=10.0 \%, 4=3.4 \%$, and $5=7.3 \%$ ). Pearson correlation coefficients of these two traits were nonsignificant, possibly due to the small sample size.
Of most interest were the subjective ratings made by Mr. Fangue (Table 1), the time to hand-clean the shelled samples, and the amount of shell removal from the shelled kernel samples [percent kernel (ShK\%K)]. Of the control cultivars, 'Navaho' and 'Pawnee' were rated 1 (best), above 'Desirable' (rated 3 ). This was somewhat surprising since 'Desirable' is considered to be an excellent shelling cultivar by the industry at large. Overall, there seemed to be little or no general parental effects upon shellability of different clones because full sibs often differed markedly in rating and other parameters.

The quantitative measurements of the kernel and shell samples from the sheller (Fig. 1) were compared using visual ratings as treatments (Table 2). Time required to hand-clean the kernel sample showed significant differences among the five visual rating classes. The 


\section{Eight trees representing a single entry}

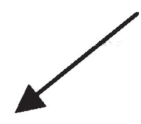

From each tree: 5 nut sample with measurements on each nut:

Nut length (NL)

Nut width (NWth)

Nut length:width ratio (NL:NWth)

Nut height $(\mathrm{NH})$

Nut length:height ratio (NL:NH)

Nut weight (NW)

Nut buoyancy (NB)

Nut volume (NV)

Nut density (ND)

Kernel weight (KW)

Kernel \% (K\%)

Shell weight:nut volume (ShWt:NV)

Dorsal groove packing \% (DGP\%)

Ventral groove packing \% (VGP\%)

Fuzz \% (Fz\%)

Kernel color (KC)

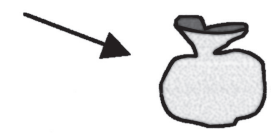

$3 \mathrm{~kg}$ bulk sample

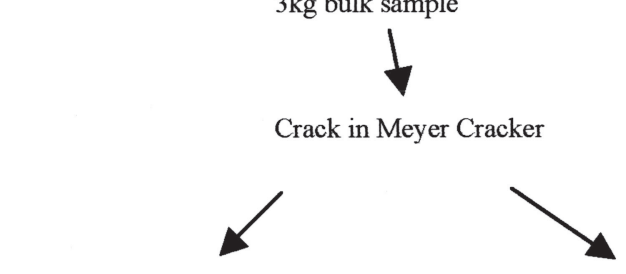

$.5 \mathrm{~kg}$ Cracked Sample

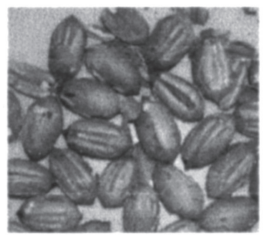

Total weight

Weight of shell fragments
Shell $2.5 \mathrm{~kg}$ sample in Thomson Sheller, which produces two samples: one primarily kernels (but with some shell fragments), the other primarily shell fragments (but with some kernel pieces).

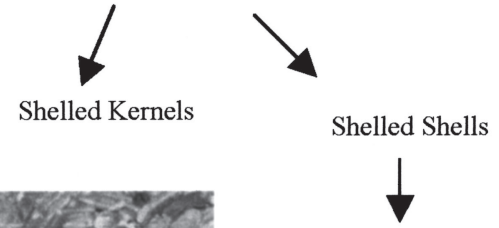

Remove kernel pieces Percent kernel (ShShK\%)
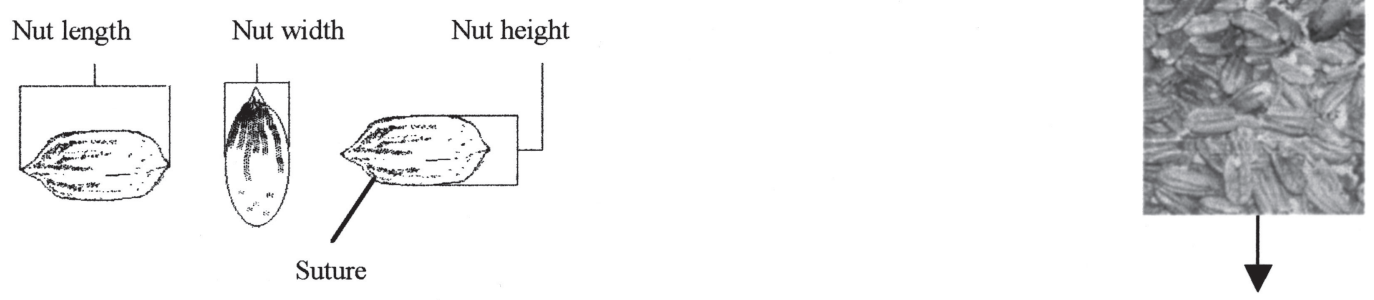

Record following:

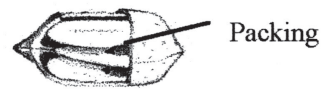

Visual rating, 1-5 (Rating)

Cleaning time (Time)

Percent kernel (ShK\%K)

Dorsal groove retention (ShDGP\%)

Ventral groove retention (ShVGP\%)

Damaged Shoulders (ShDSh\%)

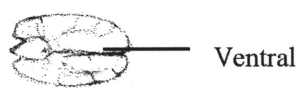

Divide into 4 portions

1. Complete halves, at least $80 \%$ intact $(\mathrm{CH} \%)$

2. Large pieces, $80 \%$ to $50 \%$ intact (LP\%)

3. Small pieces, $50 \%$ to $25 \%$ intact (SP\%)

4. Chips, $<25 \%$ intact (Chips\%)

Fig. 1. Flow diagram of pecan shelling procedure. Notations in parenthesis are used in tables and elsewhere to refer to these parameters.

accuracy of these visual ratings made by Mr. Fangue was impressive, and reflects years of hand-cleaning of samples from the sheller.

The percent kernel (ShK\%K) was highest for the lowest visual ratings (Table 2). This is logical because the higher percent samples would exhibit greater kernel visibility, with shell parts less obvious.

Surprisingly, the visual ratings for percent dorsal (ShDGP\%) and ventral groove packing material (ShVGP\%) did not differ significantly. This is a routine measurement made on all samples in all phases of the breeding program, both BBP and NPACTS. Perhaps this lack of difference reflects strong past selection of the USDA-advanced selections in this test. Overall, the percentages of foreign material retained were low.

A major evaluation criterion in all pecan shelling operations is final kernel piece size, with a premium often being paid for intact halves or large pieces. All four measurements of kernel size differed for visual ratings. Percent intact halves $(\mathrm{CH} \%)$ showed strong association with visual ratings, with a $>30 \%$ difference between visual ratings 1 and 5. A near-perfect inverse relationship to percent intact halves is shown for the other three kernel sizes. This inverse relationship must reflect the large quantity of kernel in intact halves for the lower visual ratings. There was an $\approx 6$-fold increase between ratings 1 and 5 for percent chips (the least valuable kernel size pieces by weight (Table 2)).

Damaged kernel shoulders (ShDSh\%) showed nonsignificance, although an interesting trend is present. Perhaps with more samples, this measurement could be significant and useful. This damage is sheller related, in that the pressure to crack the nuts is closely dependent upon shell strength, nut shape, and many other factors. Skill in setting the sheller for each specific nut sample may have been a source of error in this determination.

The proportion of kernel that came out of 

not differ significantly between different visual rating classes (Table 2). The $4 \%$ to $7 \%$ kernel in this fraction is of economic importance to large shelling operations, and techniques to recover at least a portion of this kernel is routine. Obviously, the lower percentages are desirable in any shelling operation.

Nut quality data taken from individual nuts collected from each of eight trees were evaluated in relation to visual rating classes (Table 3 ). Nut density (ND), kernel color (KC), and shell weight ratio to nut volume (ShWt:NV) differed with visual ratings. The less dense nuts shelled better, indicating that internal air spaces contribute to ease of shelling. Breeders have always considered high nut density as a quality attribute, but perhaps there is an upper limit that should not be exceeded in the genetic selection process. Romberg (1952) suggested that cultivars could differ in shell thickness per nut volume, which would reduce kernel percentages but increase nut density. This parameter was positively correlated with visual rating classes (Table 4). As shell weight per volume of nuts increased, the shelling rating increased (poorer performance). The shell thickness per nut volume was the single best predictor of shelling performance of all parameters determined in the nut quality analysis, despite the fact that the parameter varied over a narrow range (Table 1). As shell weight per nut volume increased, the time required to shell the samples increased, the shelled percent kernel decreased, the percent complete halves decreased, the percent of all size classes for pieces increased, and the amount of shoulder damage increased (Table 4). Kernel color (KC) differed between visual rating classes (Table 3), with the best ratings (lower values) being brighter. In pecan, dark color of kernels is associated with nut age (Grauke et al., 1998), which leads to rancidity. This association is reflected in the visual ratings made by Ken Fangue.

Other nut quality measurements were not related to visual ratings (Table 3 ). Nut shape (NL, NWth, NL:NWth, NH, NL:NH) was not related to visual ratings. Grauke and Thompson (1997) used the ratio of nut length the sheller with the shell fraction (ShShK\%) did

to nut height to describe pecan nut shape, in the following ranking: 1 to $1.39=$ orbicular; 1.40 to 1.59 and widest at base $=$ ovate; 1.40 to 1.59 and widest at apex = obovate; 1.40 to 1.59 and widest in middle $=$ oval elliptic; 1.60 to $1.79=$ elliptic; 1.80 to $1.99=$ oblong elliptic; $>2.00=$ oblong. Using that scale, samples in this test ranged from orbicular to oblong, the entire range of the scale, but did not differ in shelling performance (Table 1). Standard nut and kernel lab measurements, such as nut weight (NW), buoyancy (NB), volume (NV); or kernel weight $(\mathrm{KW})$ or percent $(\mathrm{K} \%)$ had no bearing on ease of shelling. Especially surprising is the absence of effect for percent kernel. Nuts in this test ranged from $45.5 \%$ kernel (86-02-0486) to $64.9 \%$ kernel (86-030505) (Table 1). The ratio of kernel to shell affects many economic traits, such as value per pound, and is considered a strong indicator of nut quality, but did not impact shelling performance in this test.

Many traits were correlated (Table 4), with values statistically significant at any level $(P<$ $0.05)$ shown in bold type. The hand-cleaning time (time) varies in relation to the different visual rating classes (rating), which is in general agreement with above results. Rating classes were negatively related to percent kernel in the kernel sample out of the sheller (ShK\%K), as expected. There was also a negative association between visually rated class and percent complete halves $(\mathrm{CH} \%)$, meaning that the lower, or better the rating, the higher this percent. Positive relationships existed between rating and the other three sizes of kernel pieces [large pieces (LP\%), small pieces (SP\%), and chips (Chips\%)]. As discussed above, this inverse association must result from a large proportion of the shelled kernels remaining in complete halves.

The percent kernel in the shell portion out of the sheller (ShShK\%) (Fig. 1) was related only to the percent chips (Chips\%) in the kernel portion out of the sheller. This is logical because smaller pieces have a greater tendency to be blown out with the shell fragments.

The amount of packing material retained in the ventral groove (ShVGP\%) was negatively

Table 2. Shelling test evaluation parameter means for five visual rating classes. See Fig. 1 for definition of parameters.

Visual Time

rating $\left(\min \cdot \mathrm{kg}^{-1}\right) \mathrm{ShK} \% \mathrm{~K} \quad \mathrm{ShDGP} \% \quad \mathrm{ShVGP} \% \quad \mathrm{CH} \% \quad \mathrm{LP} \% \quad \mathrm{SP} \% \quad \mathrm{Chips} \% \quad \mathrm{ShDSh} \% \quad \mathrm{ShShK} \%$

\begin{tabular}{rrrrrrrrrrr}
\hline 1 & $55 \mathrm{~b}^{2}$ & $88 \mathrm{a}$ & $0.50 \mathrm{a}$ & $0.50 \mathrm{a}$ & $82 \mathrm{a}$ & $12 \mathrm{~b}$ & $3 \mathrm{c}$ & $0.9 \mathrm{c}$ & $37 \mathrm{a}$ & $4.4 \mathrm{a}$ \\
2 & $60 \mathrm{~b}$ & $85 \mathrm{a}$ & $0.11 \mathrm{a}$ & $0.44 \mathrm{a}$ & $72 \mathrm{ab}$ & $19 \mathrm{ab}$ & $6 \mathrm{bc}$ & $2.1 \mathrm{bc}$ & $44 \mathrm{a}$ & $3.2 \mathrm{a}$ \\
3 & $67 \mathrm{~b}$ & $78 \mathrm{~b}$ & $0.38 \mathrm{a}$ & $0.00 \mathrm{a}$ & $60 \mathrm{bc}$ & $26 \mathrm{a}$ & $9 \mathrm{~b}$ & $2.6 \mathrm{bc}$ & $48 \mathrm{a}$ & $3.8 \mathrm{a}$ \\
4 & $76 \mathrm{~b}$ & $75 \mathrm{~b}$ & $0.00 \mathrm{a}$ & $0.00 \mathrm{a}$ & $49 \mathrm{c}$ & $27 \mathrm{a}$ & $19 \mathrm{a}$ & $3.9 \mathrm{ab}$ & $45 \mathrm{a}$ & $4.6 \mathrm{a}$ \\
5 & $114 \mathrm{a}$ & $73 \mathrm{~b}$ & $0.33 \mathrm{a}$ & $0.00 \mathrm{a}$ & $49 \mathrm{c}$ & $28 \mathrm{a}$ & $16 \mathrm{a}$ & $5.6 \mathrm{a}$ & $70 \mathrm{a}$ & $6.8 \mathrm{a}$ \\
\hline
\end{tabular}

${ }^{\mathrm{z}}$ Means within columns with a common letter are not significantly different according to Duncan's multiple range test, $P<0.05$.

Table 3. Mean nut parameters of replicated nut and kernel samples from Brownwood, Texas, NPACTS test. See Fig. 1 for definition of parameters.

\begin{tabular}{|c|c|c|c|c|c|c|c|c|c|c|c|c|c|c|c|c|}
\hline Rating & $\begin{array}{c}\mathrm{NL} \\
(\mathrm{mm})\end{array}$ & $\begin{array}{l}\text { NWth } \\
(\mathrm{mm})\end{array}$ & $\begin{array}{c}\text { NL:NWth } \\
\left(\mathrm{NL} \cdot \mathrm{NWth}^{-1}\right)\end{array}$ & $\begin{array}{c}\mathrm{NH} \\
(\mathrm{mm})\end{array}$ & $\begin{array}{c}\mathrm{NL}: \mathrm{NH} \\
\left(\mathrm{NL} \cdot \mathrm{NH}^{-1}\right)\end{array}$ & $\begin{array}{c}\text { NW } \\
(\mathrm{g})\end{array}$ & $\begin{array}{l}\text { NB } \\
(\mathrm{g})\end{array}$ & $\begin{array}{l}\mathrm{NV} \\
(\mathrm{mL})\end{array}$ & $\begin{array}{c}\mathrm{ND} \\
\left(\mathrm{g} \cdot \mathrm{mL}^{-1}\right)\end{array}$ & $\begin{array}{c}\mathrm{KW} \\
(\mathrm{g})\end{array}$ & $\begin{array}{l}\mathrm{K} \% \\
(\%)\end{array}$ & $\begin{array}{c}\text { DGP\% } \\
(\%)\end{array}$ & $\begin{array}{c}\text { VGP\% } \\
(\%)\end{array}$ & $\begin{array}{c}\mathrm{Fz} \% \\
(\%)\end{array}$ & $\begin{array}{c}\mathrm{KC} \\
(1-5)\end{array}$ & $\begin{array}{c}\text { ShWt:NV } \\
\left(\mathrm{ShWT} \mathrm{NV}^{-1}\right)\end{array}$ \\
\hline 1 & $44 a^{z}$ & $24 a$ & $1.8 \mathrm{a}$ & $24 a$ & $1.9 \mathrm{a}$ & $11.4 \mathrm{a}$ & $2.8 \mathrm{a}$ & $12 \mathrm{a}$ & $0.78 \mathrm{~b}$ & $5.4 \mathrm{a}$ & $56 \mathrm{a}$ & $3.1 \mathrm{a}$ & $13 \mathrm{a}$ & $7.4 \mathrm{a}$ & $2.7 \mathrm{~b}$ & $0.34 \mathrm{~b}$ \\
\hline 2 & $43 \mathrm{a}$ & $24 a$ & $1.8 \mathrm{a}$ & $24 \mathrm{a}$ & $1.8 \mathrm{a}$ & $10.5 \mathrm{a}$ & $2.5 \mathrm{a}$ & $13 \mathrm{a}$ & $0.81 \mathrm{ab}$ & $6.1 \mathrm{a}$ & $58 \mathrm{a}$ & $4.1 \mathrm{a}$ & $12 \mathrm{a}$ & $5.5 \mathrm{a}$ & $2.9 \mathrm{ab}$ & $0.34 \mathrm{~b}$ \\
\hline 3 & $44 \mathrm{a}$ & $25 a$ & $1.8 \mathrm{a}$ & $25 \mathrm{a}$ & $1.8 \mathrm{a}$ & $10.9 \mathrm{a}$ & $3.0 \mathrm{a}$ & $13 \mathrm{a}$ & $0.79 \mathrm{ab}$ & $5.9 \mathrm{a}$ & $55 \mathrm{a}$ & $3.4 \mathrm{a}$ & $14 \mathrm{a}$ & $7.4 \mathrm{a}$ & $2.9 \mathrm{ab}$ & $0.35 \mathrm{ab}$ \\
\hline 4 & $44 \mathrm{a}$ & $26 a$ & $1.8 \mathrm{a}$ & $24 \mathrm{a}$ & $1.8 \mathrm{a}$ & $11.5 \mathrm{a}$ & $2.4 \mathrm{a}$ & $13 \mathrm{a}$ & $0.82 \mathrm{ab}$ & $6.6 \mathrm{a}$ & $57 \mathrm{a}$ & $5.9 \mathrm{a}$ & $10 \mathrm{a}$ & $8.8 \mathrm{a}$ & $3.3 \mathrm{a}$ & $0.35 \mathrm{ab}$ \\
\hline 5 & $42 \mathrm{a}$ & $24 \mathrm{a}$ & $1.7 \mathrm{a}$ & $23 \mathrm{a}$ & $1.8 \mathrm{a}$ & $9.9 \mathrm{a}$ & $1.6 \mathrm{a}$ & $11 \mathrm{a}$ & $0.86 \mathrm{a}$ & $5.5 \mathrm{a}$ & $56 \mathrm{a}$ & $8.2 \mathrm{a}$ & $6 \mathrm{a}$ & $5.2 \mathrm{a}$ & $3.3 \mathrm{a}$ & $0.38 \mathrm{a}$ \\
\hline
\end{tabular}

${ }^{2}$ Means within columns with a common letter are not significantly different according to Duncan's multiple range test, $P<0.05$.

HortScience, Vol. 38(4), July 2003 related to visual ratings. This was surprising, since no significance for this trait was shown above in either the replicated lab analysis or the single mechanically shelled samples. This r value is not high, and is only significant at $P$ $=0.04$. As expected from the above data, the dorsal groove packing percent (ShDGP\%) was nonsignificant.

Kernel color (KC) was positively related to visual rating class (rating), meaning that lighter color contributed to more desirable (lower) visual ratings. This reinforces the importance of this trait to most people rating pecans. Nut density (ND) was also positively related to rating, explaining a small portion of this variability. As nut density increased, visual rating deteriorated (increased).

Time to hand-clean kernel samples out of the sheller (time) was negatively related to shelled kernel percent (ShK\%K) and percent complete halves $(\mathrm{CH} \%)$, and positively related to percent large pieces (LP\%), percent small pieces (SP\%), percent chips (Chips\%), and kernel color $(\mathrm{KC})$. All of these relationships are similar to those for visual ratings discussed above. Nut density (ND) was not significantly correlated with cleaning time (time) as visual rating (rating) was.

Shelled kernel percent (ShK\%K) correlations were very similar to those for visual rating (rating) and cleaning time (time). This characteristic was studied earlier in the NPACTS program (Thompson et al., 1989), and shown to be negatively associated with nut buoyancy, kernel percent fuzz, dorsal groove width, and dorsal groove packing retention. It was positively related to nut density and dorsal groove packing percentage.

The measurements of degree to which kernels broke up during the shelling process [percent complete halves $(\mathrm{CH} \%)$, percent large pieces (LP\%), percent small pieces (SP\%), and percent chips (Chips\%)], were related to many other measurements. Generally, if the relationship with one of these traits was positive for percent complete halves $(\mathrm{CH} \%)$, it was negative for the other three kernel size measurements. The reverse effect was also evident. The relationships of these four kernel size classes with nut shape measurements were often significant. For example, there was no relationship between nut length (NL) and percent complete halves $(\mathrm{CH} \%)$, but there was a negative relationship between percent complete halves and nut width (NWth) and nut height $(\mathrm{NH})$. Importance of nut width in determining kernel breakup is also shown by percent complete halves $(\mathrm{CH} \%)$ being negatively related to nut width and height, meaning that nuts with greater diameters produced lower percentages of complete halves. The positive 
Table 4. Pearson correlation values (r) for pecan shelling traits. See Fig. 1 for definition of parameters. Values that are significant at any level $(P<0.05,0.01$, or 0.001 ) are in bold type.

\begin{tabular}{|c|c|c|c|c|c|c|c|c|c|c|c|c|c|c|}
\hline 1 & Rating & & & & & & & & & & & & & \\
\hline 2 & Time & 0.546 & & & & & & & & & & & & \\
\hline 3 & ShK\%K $(\%)$ & -0.732 & -0.556 & & & & & & & & & & & \\
\hline 4 & $\operatorname{ShShK} \%(\%)$ & 0.105 & 0.244 & -0.140 & & & & & & & & & & \\
\hline 5 & $\mathrm{CH} \%(\%)$ & -0.671 & -0.485 & 0.577 & -0.128 & & & & & & & & & \\
\hline 6 & $\mathrm{LP} \%(\%)$ & 0.550 & 0.287 & -0.477 & 0.054 & -0.950 & & & & & & & & \\
\hline 7 & $\mathrm{SP} \%(\%)$ & 0.720 & 0.642 & -0.605 & 0.168 & -0.878 & 0.694 & & & & & & & \\
\hline 8 & Chips\% (\%) & 0.627 & 0.686 & -0.561 & 0.302 & -0.806 & 0.659 & 0.782 & & & & & & \\
\hline 9 & ShDGP\% (\%) & -0.047 & 0.139 & 0.073 & 0.118 & 0.240 & -0.300 & -0.115 & -0.082 & & & & & \\
\hline 10 & ShVGP\% (\%) & -0.298 & 0.104 & 0.291 & 0.205 & 0.127 & -0.119 & -0.114 & -0.105 & 0.317 & & & & \\
\hline 11 & ShDSh\% $(\%)$ & 0.279 & 0.124 & -0.128 & 0.152 & -0.227 & 0.262 & 0.082 & 0.286 & 0.016 & 0.008 & & & \\
\hline 12 & NL (mm) & -0.039 & -0.223 & -0.050 & 0.026 & -0.009 & 0.054 & -0.042 & -0.087 & -0.184 & -0.295 & -0.178 & & \\
\hline 13 & NWth (mm) & 0.136 & 0.078 & -0.356 & 0.110 & -0.575 & 0.601 & 0.427 & 0.396 & -0.096 & 0.062 & -0.133 & 0.079 & \\
\hline 14 & NL:NWth & -0.118 & -0.221 & 0.173 & -0.030 & 0.322 & -0.300 & -0.281 & -0.300 & -0.104 & -0.272 & -0.066 & 0.809 & \\
\hline 15 & $\mathrm{NH}(\mathrm{mm})$ & 0.060 & -0.048 & -0.232 & 0.084 & -0.470 & 0.505 & 0.349 & 0.258 & -0.232 & 0.113 & -0.125 & -0.010 & \\
\hline 16 & $\mathrm{NL}: \mathrm{NH}$ & -0.079 & -0.107 & 0.129 & -0.030 & 0.315 & -0.305 & -0.270 & -0.247 & 0.027 & -0.271 & -0.035 & 0.721 & \\
\hline 17 & NW (g) & 0.179 & -0.089 & -0.330 & -0.028 & -0.505 & 0.524 & 0.396 & 0.313 & -0.314 & -0.187 & -0.208 & 0.458 & \\
\hline 18 & NB $(g)$ & -0.164 & -0.149 & -0.040 & 0.096 & -0.166 & 0.242 & 0.032 & 0.023 & 0.039 & 0.124 & -0.230 & 0.459 & \\
\hline 19 & $\mathrm{KC}$ & 0.385 & 0.359 & -0.377 & 0.191 & -0.280 & 0.150 & 0.391 & 0.424 & -0.076 & -0.038 & 0.247 & 0.052 & \\
\hline 20 & KW (g) & 0.124 & -0.163 & -0.198 & -0.091 & -0.384 & 0.382 & 0.333 & 0.229 & -0.343 & -0.175 & -0.275 & 0.363 & \\
\hline 21 & DGP\% $(\%)$ & 0.225 & 0.058 & 0.038 & -0.112 & -0.052 & 0.038 & 0.075 & 0.018 & 0.019 & 0.163 & 0.294 & 0.051 & \\
\hline 22 & VGP\% (\%) & -0.107 & -0.208 & 0.030 & -0.054 & 0.117 & -0.086 & -0.119 & -0.177 & -0.078 & 0.039 & 0.141 & -0.379 & \\
\hline 23 & $\mathrm{Fz} \%(\%)$ & -0.017 & 0.092 & -0.070 & 0.262 & -0.002 & -0.010 & 0.012 & 0.034 & 0.096 & 0.161 & -0.092 & 0.460 & \\
\hline 24 & $\mathrm{NV}(\mathrm{ml})$ & 0.061 & -0.133 & -0.264 & 0.022 & -0.450 & 0.499 & 0.308 & 0.240 & -0.216 & -0.084 & -0.259 & 0.543 & \\
\hline 25 & $\mathrm{ND}\left(\mathrm{g} \cdot \mathrm{mL}^{-1}\right)$ & 0.333 & 0.126 & -0.184 & -0.152 & -0.141 & 0.078 & 0.202 & 0.179 & -0.218 & -0.254 & 0.165 & -0.270 & \\
\hline 26 & $\mathrm{~K} \%(\%)$ & -0.099 & -0.168 & 0.233 & -0.207 & 0.202 & -0.248 & -0.087 & -0.126 & -0.125 & -0.001 & -0.172 & -0.214 & \\
\hline \multirow[t]{2}{*}{27} & ShWt:NV & 0.412 & 0.299 & -0.440 & 0.079 & -0.377 & 0.369 & 0.303 & 0.332 & -0.070 & -0.232 & 0.343 & 0.001 & \\
\hline & & 1 & 2 & 3 & 4 & 5 & 6 & 7 & 8 & 9 & 10 & 11 & 12 & \\
\hline 14 & NL:NWth & -0.519 & & & & & & & & & & & & \\
\hline 15 & $\mathrm{NH}(\mathrm{mm})$ & 0.725 & -0.432 & & & & & & & & & & & \\
\hline 16 & NL:NH & -0.445 & 0.881 & -0.694 & & & & & & & & & & \\
\hline 17 & NW (g) & 0.712 & -0.031 & 0.770 & -0.212 & & & & & & & & & \\
\hline 18 & $\mathrm{NB}(\mathrm{g})$ & 0.553 & 0.067 & 0.421 & 0.032 & 0.373 & & & & & & & & \\
\hline 19 & $\mathrm{KC}$ & 0.080 & 0.003 & -0.064 & 0.077 & 0.123 & -0.209 & & & & & & & \\
\hline 20 & KW (g) & 0.552 & -0.025 & 0.615 & -0.177 & 0.909 & 0.122 & 0.135 & & & & & & \\
\hline 21 & DGP\% $(\%)$ & -0.235 & 0.179 & -0.198 & 0.164 & -0.046 & -0.230 & 0.088 & 0.024 & & & & & \\
\hline 22 & VGP\% $\%(\%)$ & -0.062 & -0.291 & -0.037 & -0.252 & -0.222 & -0.281 & 0.043 & -0.198 & -0.032 & & & & \\
\hline 23 & $\mathrm{Fz} \%(\%)$ & 0.048 & 0.378 & -0.002 & 0.348 & 0.037 & 0.604 & 0.016 & -0.086 & -0.128 & -0.376 & & & \\
\hline 24 & NV (mL) & 0.776 & 0.005 & 0.764 & -0.147 & 0.910 & 0.724 & -0.009 & 0.731 & -0.139 & -0.292 & 0.296 & & \\
\hline 25 & $\mathrm{ND}\left(\mathrm{g} \cdot \mathrm{mL}^{-1}\right)$ & -0.200 & -0.118 & -0.039 & -0.169 & 0.132 & -0.855 & 0.258 & 0.345 & 0.241 & 0.179 & -0.633 & -0.284 & \\
\hline 26 & $\mathrm{~K} \%(\%)$ & -0.274 & -0.041 & -0.261 & 0.011 & -0.084 & -0.560 & 0.040 & 0.330 & 0.181 & 0.054 & $-\mathbf{0 . 3 5 7}$ & -0.313 & 0.563 \\
\hline 27 & ShWt:NV & 0.159 & -0.075 & 0.283 & -0.182 & 0.263 & -0.168 & 0.230 & -0.008 & 0.029 & 0.124 & -0.226 & 0.120 & $0.324-0.591$ \\
\hline & & 13 & 14 & 15 & 16 & 17 & 18 & 19 & 20 & 21 & 22 & 23 & 24 & 25 \\
\hline
\end{tabular}

relationships between the ratios of nut length to width (NL:NWth) and nut length to height (NL:NH) also indicate that as these ratios increase, percent complete halves increase. The ratios would be less as nut width and height increase.

As kernel weight (KW) or nut density (ND) increased, percent complete halves $(\mathrm{CH} \%)$ decreased and the other size classes increased. This was unexpected, and may emphasize the importance of adequate air spaces within the nuts, as discussed above. The overall high nut quality of these samples probably influenced this result.

Proportion of damaged shoulders (ShDSh\%) was related to proportion of chips (Chips\%), as expected. This parameter was also associated with increased packing material retained in the dorsal grooves (ShDGP\%). Longer nuts were heavier, more buoyant, and had heavier kernels, as expected (Table 4). These nuts also had less ventral groove packing (ShVGP\%), but greater percentages of fuzz (Fz\%). Higher nut buoyancy (NB) was also related to higher percent fuzz, both characteristics being indicative of low quality.

Overall, we were impressed with the accuracy of the quick visual rating made by Mr.
Fangue. His rating was closely correlated with the major nut evaluation characteristics that objectively measure cracking and shelling efficiency, such as percent kernel of kernel fraction out of sheller, time required to hand-clean kernel samples, degree of kernel breakup during shelling, and kernel color. Other characteristics, such as retention of packing material in dorsal and ventral grooves, seem to have little bearing on overall shelling efficiency, but this may be due to successful selection prior to this shelling evaluation. Many of the above routine measurements performed in the standard USDA pecan breeding program require tremendous effort and time. These results indicate that many of these evaluations are of limited value and do not merit the effort required. However, the calculation of the shell weight per nut volume is an excellent predictor of shelling performance. That parameter requires several direct measurements for its calculation, but out performs each of those measurements in its correlation to shelling performance. These results should help to refine and improve the USDA pecan breeding program, as well as provide insight for shelling plant operators in determining nut and kernel characteristics of prime importance in predicting shellability and nut value.

\section{Literature Cited}

Grauke, L.J. and T.E. Thompson. 1996. Pecans and hickories, p. 185-239. In: J.A. Janick and J.N. Moore (eds.). Fruit breeding - III. Nuts. Wiley, New York.

Grauke, L.J., T.E. Thompson, E.F. Young, Jr., and H.D. Petersen. 1998. The effect of year, cultivar, location, and storage regime on pecan kernel color. J. Amer. Soc. Hort. Sci. 123:681-686.

Grauke, L.J. and T.E. Thompson. 1997. Pecan, p. 544-562. In: Brooks and Olmo register of fruit and nut varieties, 3rd ed. ASHS Press, Alexandria, Va.

Romberg,L.D. 1952. Measurement of the filling of pecan nuts. Texas Pecan Growers Assn. 31:35-42.

Thompson, T.E. and L.J. Grauke. 1991. Pecans and other hickories (Carya), p. 839-904. In: J.N. Moore and J.R. Ballington (eds.). Genetic resources of temperate fruit and nut crops. Intl. Soc. Hort. Sci., Wageningen.

Thompson, T.E., L.J. Grauke, and E.F. Young, Jr. 1996. Pecan kernel color: Standards using the Munsell system of color notation. J. Amer. Soc. Hort. Sci. 121:548-553.

Thompson, T.E. and E.F. Young, Jr. 1985. Pecan cultivars: Past and present. Texas Pecan Growers Assn., College Station.

Waugh, J.G. 1938. Approximate specific gravity determination, a rapid method for use with pecans and similar small objects. Ind. and Eng. Chem. 10:209-211. 